\title{
O impacto da profissionalização nas associações de consumidores - o caso da DECO
}

The Impact of Professionalization on Consumer Associations - The Case of DECO L'impact de la professionnalisation dans les associations de consommateurs - le cas DECO

\section{Raquel Rego}

\section{OpenEdition}

\section{Journals}

\section{Edição electrónica}

URL: http://journals.openedition.org/rccs/1783

DOl: $10.4000 /$ rccs. 1783

ISSN: 2182-7435

\section{Editora}

Centro de Estudos Sociais da Universidade de Coimbra

Edição impressa

Data de publição: 1 Setembro 2010

Paginação: 113-132

ISSN: 0254-1106

\section{Refêrencia eletrónica}

Raquel Rego, «O impacto da profissionalização nas associações de consumidores - o caso da DECO », Revista Crítica de Ciências Sociais [Online], 90 | 2010, colocado online no dia 01 outubro 2012, criado a 02 maio 2019. URL : http://journals.openedition.org/rccs/1783 ; DOI : 10.4000/rccs.1783 


\title{
RAQUEL REGO
}

\section{O impacto da profissionalização nas associações de consumidores - o caso da DECO}

\begin{abstract}
A literatura científica sustenta que a acção das associações de consumidores é enfraquecida por factores inerentes ao consumo, como a sua heterogeneidade, e por factores externos, como a existência de outras organizações com interesses próximos. A análise das próprias associações de consumidores como um meio para compreender as dificuldades da acção colectiva parece ser desprezada. A partir de um estudo de caso, demonstramos que a profissionalização transforma a associação e contribui nomeadamente para a permanência dos dirigentes no poder. Os nossos resultados contribuem assim, não só para compreender os constrangimentos da acção colectiva consumidorista, e em particular das associações de consumidores do modelo anglo-saxónico dominante, mas também para reflectir sobre as consequências da profissionalização das associações voluntárias de um modo geral.
\end{abstract}

Palavras-chave: associativismo e poder; consumidorismo; dirigentes associativos; profissionalização; síndrome do fundador.

\section{Introdução}

A globalização cria novos desafios para a protecção do consumidor, desde a proliferação de estilos de consumo à emergência de concorrência entre as organizações de consumidores e outras entidades. ${ }^{1}$ Com efeito, estas organizações, que lutam há décadas, a nível nacional e internacional, para influenciar as medidas de regulação que afectam os interesses dos consumidores, enfrentam hoje a concorrência de outras organizações, quer de ONG, como as da área ambiental, quer das próprias empresas (Ronit, 2007) que promovem por exemplo linhas de apoio ao cliente.

Além dos factores externos, a protecção dos consumidores depara-se com desafios específicos da sua acção colectiva, designadamente dificuldades

\footnotetext{
${ }^{1}$ Como observa Jean-Yves Trépos (1982), o movimento de consumidores é composto não apenas por associações, mas por vários tipos de organizações, daí usarmos o termo organização em lugar de associação.
} 
em mobilizar os consumidores e avaliar a sua capacidade de sanção, uma vez que o consumo é, antes de mais, um comportamento individual. No entanto, neste âmbito, a literatura científica tem desprezado a análise do funcionamento interno das organizações de consumidores.

Ora, questionar a organização é uma forma de compreender as dificuldades da acção colectiva (Crozier e Friedberg, 1977). Foi assim que decidimos centrar a nossa análise nos dirigentes associativos, isto é, nos membros da Direcção das associações de consumidores (de pessoas individuais, de adesão voluntária, de direito privado, sem fins lucrativos), com o intuito de contribuir para a compreensão dos seus problemas de acção colectiva.

Os dirigentes são os actores sociais mais influentes numa associação, quer pelos direitos resultantes do quadro legal que lhes atribui uma função executiva, quer pelas práticas que demonstram uma maior participação, desde logo ao nível da representação externa da associação. Procurámos por isso conhecer a relação que os dirigentes estabelecem com a associação e saber até que ponto contribuem e reflectem a sua mudança. A operacionalização dos nossos objectivos impunha assim adoptarmos uma perspectiva longitudinal, de modo a apreender a mudança do envolvimento dirigente (Trépos, 1982).

Em termos empíricos analisamos um caso, a Associação Portuguesa de Defesa do Consumidor (DECO), onde fizemos 42 entrevistas em profundidade aos seus dirigentes, o que representa praticamente a totalidade $^{2}$ desde a sua fundação, em 1974, até 2005 (Rego, 2007). Para além disso, fizemos análise documental, principalmente a partir dos relatórios de actividade da associação, dos estatutos e suas revisões e da revista Proteste. Importa notar também que a partir deste caso foi recolhida informação sobre as associações homólogas francesa e belga que nos permitiu levantar a hipótese da existência de um perfil de dirigente comum a estes diversos contextos.

Este texto tem três partes principais: num primeiro momento destacamos a literatura que enquadra o nosso objecto de estudo, nomeadamente dando conta de como a ideologia associativa nos impede de compreender a diversidade do fenómeno associativo e de como a síndrome do fundador é um conceito útil na análise do processo de mudança associativa; depois apresentamos o contexto onde se integra o nosso estudo de caso,

\footnotetext{
${ }^{2}$ A partir de documentos da DECO e através de uma abordagem tipo bola-de-neve, foram identificados 50 dirigentes ao longo dos mandatos do nosso período de observação (1974-2005). Os indivíduos que não foi possível entrevistar faleceram, vivem no estrangeiro, recusaram ou foram identificados tardiamente.
} 
em particular o modelo consumidorista ${ }^{3}$ anglo-saxónico dominante e o movimento de consumidores português; finalmente, discutimos os resultados do nosso estudo empírico que sustentam que a profissionalização da associação transforma a associação e que estas mudanças estão estreitamente relacionadas com o recrutamento e o envolvimento dos seus dirigentes.

\section{A ideologia associativa como obstáculo epistemológico}

A partir da década de 1990, as mudanças sociais e políticas, mais do que a teoria democrática, parecem ter imposto as associações como objecto de estudo. Com efeito, a crise do Estado-Providência e da democracia representativa, atestada por exemplo nas elevadas taxas de abstenção eleitoral, levaram cientistas sociais e políticos a buscar uma terceira via entre o Estado e o mercado (Cohen e Rogers, 1995).

Ao mesmo tempo, a globalização, a diferenciação, a complexidade e a reflexividade crescentes contribuíram para uma apetência maior dos indivíduos a juntar forças e afirmar a sua identidade (Warren, 2001). Defendeu-se então inclusivamente a existência de uma revolução associativa global

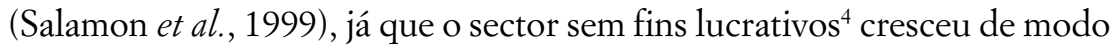
significativo, a julgar por alguns indicadores económicos, nomeadamente a taxa de emprego e a contribuição do sector para o PIB.

Apesar das múltiplas críticas à circularidade do seu raciocínio (Newton, 2002), o trabalho de Robert Putnam (1994), Making Democracy Work, desempenhou um papel fundamental, não só na disseminação do conceito de capital social (enquanto redes sociais com valores e confiança que promovem a cooperação), mas também na sua vinculação ao associativismo e sobretudo às associações horizontais, onde o capital social se acumula mais depressa e a cooperação se desenvolve mais facilmente.

Em todo o caso, a teoria do capital social pode ser considerada apenas a mais proeminente das correntes da chamada democracia associativa. No quadro da reflexão sobre o funcionamento da democracia, o que inclui

\footnotetext{
${ }^{3}$ Utiliza-se aqui a expressão consumidorismo para designar os movimentos e as acções de defesa e organização dos interesses do consumidor, assim como os que apelam a um consumo ético e responsável, que têm vindo a ganhar expressão crescente nas últimas décadas. Trata-se de uma questão distinta da que é vulgarmente significada pela palavra consumismo, que remete em regra para a prática do consumo, a propensão ao consumo excessivo ou as doutrinas defensoras das vantagens da expansão ilimitada do consumo.

${ }^{4} \mathrm{Na}$ literatura anglo-saxónica, o termo association assume um sentido amplo, pelo que podemos aqui fazer-lhe corresponder o sector não lucrativo. A literatura francófona tende a referir-se à association em sentido restrito, circunscrevendo-se inclusivamente às associações com personalidade jurídica.
} 
pluralistas, republicanos e neoliberais, ${ }^{5}$ deparamo-nos com a emergência desta perspectiva normativa que enfatiza a participação através das associações (Cohen e Rogers, 1995).

Os pilares desta perspectiva são os papéis sociais atribuídos às associações pelo menos desde a obra De la Démocratie en Amérique de Alexis de Tocqueville. ${ }^{6}$ Por um lado, ao nível interno, as associações são entendidas como uma escola da democracia, ao promover a participação dos indivíduos; por outro lado, externamente, as associações permitem mediar e representar o indivíduo junto do Estado, contribuindo para a equidade social.

Ora, uma das contribuições mais importantes geradas pelo debate em torno da democracia associativa foi chamar a atenção para o facto de ser difícil generalizar as funções e os efeitos das associações. Neste sentido, podemos falar da natureza bíbrida das associações e dizer que o que se pode generalizar é apenas a sua experiência de pluralidade (Rosenblum, 2000). ${ }^{7}$ O ideal é que haja mesmo uma diversidade de efeitos para se conseguir uma democracia sólida, ou o que Mark Warren (2001) chamou uma ecologia democrática de associações.

Considerar que as associações são todas equivalentes, na medida em que são um contrapoder, sadio e corrector, e que ser militante associativo significa ajudar os outros é, como Martine Barthélemy (1994) observa, um sinal de ideologia associativa. De facto, a ideologia associativa impede-nos de ver a diversidade da vida associativa e leva-nos a considerar a priori as associações como boas para a democracia. A ideologia associativa é, por conseguinte, um obstáculo epistemológico que tem de ser ultrapassado para podermos analisar as associações enquanto organizações que se transformam também.

Em suma, o debate sobre o associativismo dinamizou-se recentemente, sobretudo no âmbito da ciência política anglo-saxónica e da sociologia francófona do militantismo. Apesar das chamadas de atenção para a heterogeneidade destas organizações, poucos estudos empíricos dão conta da diversidade, isto é, da transformação das próprias associações.

\footnotetext{
${ }^{5}$ As classificações dos grandes paradigmas são múltiplas. Encontramos propostas alternativas por exemplo na obra de Jean-Louis Laville e de Renaud Sainsaulieu (1997), ou na de Mark Warren (2001). ${ }^{6}$ Para uma análise mais pormenorizada sobre as implicações democráticas das associações veja-se Viegas (2004).

${ }^{7}$ A heterogeneidade do tecido associativo explicará porventura a multiplicidade de tipologias sobre as associações (Marchal, 1987; Barthélémy, 1994; Salamon et al., 1999; Fillieule e Mayer, 2001; Tchernonog e Hély, 2003).
} 


\section{Analisando a mudança no interior das associações}

No quadro da sociologia das organizações, as organizações sem fins lucrativos têm merecido alguma atenção: discutem-se as fases de crescimento das associações e até se relaciona a acção dos dirigentes com as várias etapas do ciclo de vida. Com efeito, alguns autores têm analisado a relação entre liderança e gestão, sustentando que os dirigentes tendem a ratificar as directrizes formuladas por gestores, em vez de fazerem propostas por si próprios (Middleton, 1987). Outros autores têm dado atenção especial aos recursos das organizações, incluindo o maior acesso à informação proporcionado pelas multi-pertenças dos seus dirigentes (Miller-Millesen, 2003), ou pelo seu maior capital social, diríamos.

Esta literatura desenvolveu, assim, importantes prescrições normativas. ${ }^{8}$ Mas a análise sistemática da relação entre organização e dirigentes está ainda por fazer. A ausência de suporte teórico e empírico fragiliza as suas abordagens (Miller-Millesen, 2003).

Alguns conceitos parecem em todo o caso revelar um grande valor heurístico. Este é o caso da sindrome do fundador, um conceito pouco usado pela literatura científica, mas que corresponde a um fenómeno disseminado nas associações voluntárias. A sindrome do fundador ocorre quando um indivíduo (ou um pequeno grupo de indivíduos), não necessariamente fundador, lidera a associação durante uma fase difícil e tem dificuldade em aceitar a mudança (Lewis, 2002). O que caracteriza a sindrome do fundador é o conjunto de sintomas que evidencia resistência e que passam por: resistir à planificação de procedimentos; escolher pessoalmente os dirigentes; não planificar a sua sucessão. O principal sintoma é, no entanto, a ausência de tomadas de decisão a nível colectivo (Gottlieb, 2003).

Para além de traços de personalidade, existem factores externos que contribuem para a sindrome do fundador, como a contratação de pessoal para assumir funções de coordenação (Huff, 2003). A existência de pessoal remunerado pode suscitar tensões com o pessoal voluntário (Vieira, 2001), além de que a substituição de colaboradores de há muito tempo pode ser percebida como uma introdução de mudanças radicais.

Algumas medidas podem ser adoptadas para minimizar a sindrome do fundador mas ela deverá ser sobretudo prevenida através, por exemplo, da limitação do número de mandatos da Direcção, da especificação das funções dos dirigentes (Huff, 2003) ou da interdição do director (remunerado) integrar a Direcção (Lewis, 2002).

\footnotetext{
${ }^{8}$ Em Portugal é de referir por exemplo a participação no projecto Referencial Europeu do Empresário Social (Ferreira, 2005).
} 
Em suma, sabemos que os comportamentos dos dirigentes mudam com a evolução da associação e que existem resistências que podem pôr em causa a própria sobrevivência da organização. Faltam, no entanto, estudos empíricos sobre como essa transformação se processa e quais os seus efeitos.

\section{A relação ambígua entre associações de consumidores e sector lucrativo} É na medida em que o consumidor se torna um actor social que se pode dizer que estamos perante o consumidorismo. Poderíamos dizer que o consumidorismo é o conjunto de acções individuais ou colectivamente organizadas para a defesa e promoção dos interesses dos consumidores (Weiss e Chirouze, 1984: XIII). Neste sentido, o consumidorismo dá conta de todas as manifestações de defesa do consumidor, do modelo anglo-saxónico dominante ao recente consumo político ou ético ou ainda responsável. ${ }^{9}$

Centrar-nos-emos no modelo anglo-saxónico, assim chamado por ter surgido nos EUA, entre 1950 e 1970, e ter sido introduzido na Europa através da associação britânica Which.

Um dos traços distintivos deste consumidorismo é a existência de associações de consumidores, as associações de tipo consumidorista (Trépos, 1982), cuja principal actividade é a publicação de revistas. Estas revistas contêm sobretudo testes comparativos de produtos e serviços, que visam facultar informação ao consumidor sobre a melhor relação qualidade/preço para que o consumidor decida de modo informado e consciente.

$\mathrm{Na}$ maioria dos países europeus, este modelo, não só foi induzido (Freire e Silva, 1996), como é caracterizado por um processo de tipo top-down, o que quer dizer que os representantes precederam os representados (Pinto, 1990). Em França e em Portugal, por exemplo, o Estado parece desempenhar um papel importante na estimulação da sociedade civil e neste sentido, de resto, verifica-se que foi a iniciativa de altos funcionários do Estado que contribuiu para a criação das associações de consumidores respectivas. Este é o caso da francesa Union Fédéral des Consommateurs (UFC-Que Choisir), criada em 1951, e da portuguesa DECO, fundada em 1974.

Em França, o primeiro organismo público dedicado à defesa do consumidor foi o Bureau de la Consommation da Direction des Programmes

\footnotetext{
${ }^{9}$ Este novo consumidorismo, que está a crescer na Europa, tem chamado a atenção de vários autores (Micheletti et al., 2006) sobretudo por contribuir para a revisão do conceito de participação política. A sua natureza é positiva para os consumidores, dado que continuam a consumir mas fazendo escolhas éticas, ao usar o buycott em vez do boicote, nomeadamente através do labbeling scheme, isto é, da etiquetagem que conduz à compra de produtos com rótulo ecológico. Este consumidorismo continua, em todo o caso, a ser de difícil avaliação, porque pulverizado e assente na acção individual.
} 
Économiques do Ministério da Economia. Este gabinete foi criado em 1947 e dirigido por André Romieu, que foi também o primeiro presidente da associação UFC-Que Choisir, quatro anos mais tarde. ${ }^{10}$ Em Portugal, um dirigente de um departamento governamental de comércio, Alberto Regueira, torna-se também um dos dirigentes fundadores da DECO, sendo um dos seus dirigentes mais antigos.

Uma característica marcante das associações de tipo consumidorista é a cooperação entre as organizações de diferentes países, daí também a expansão do modelo. A criação de uma organização apoia-se sempre nas suas homólogas, o que se traduz no fornecimento de informação e formação, na partilha de testes comparativos e mesmo no empréstimo de dinheiro numa fase inicial, como sucedeu com a DECO.

Estas redes de associações levaram à criação de organizações internacionais, não apenas de natureza política, que pressionam os organismos europeus e mundiais no sentido de influenciarem a regulação de matérias que afectam os interesses dos consumidores (Ronit, 2007), como é o caso do Bureau Européen des Unions de Consommateurs (BEUC); mas também de natureza económica, como sucede com a holding Conseur, que se baseia numa lógica de economia de escala para realizar testes a produtos e serviços que existem nos diversos países abrangidos pela holding.

Apesar da ênfase numa imagem independente, quer política quer economicamente desinteressada, de ambas as partes, a ambiguidade está presente, como veremos, na relação entre as associações de consumidores e as organizações do sector lucrativo com quem estabelecem protocolos para a realização de testes a produtos e serviços. Esta relação já levou inclusivamente a um processo judicial no caso da Conseur e da associação italiana Altroconsumo. Com efeito, em 2006, a associação italiana perdeu o seu estatuto de associação de consumidores reconhecida pelo Estado por ordem de um tribunal devido à sua relação ambígua com o sector lucrativo e à falta de democracia interna (Cerejo, 2006).

A bolding Conseur foi criada em 1990 pela associação belga Test-Achats, tendo em vista a gestão de editoras criadas conjuntamente com associações de consumidores de vários países, sobretudo do Sul da Europa. Para além da própria Test-Achats belga, esta rede conta com: a UCO, em Espanha;

\footnotetext{
${ }^{10}$ Em rigor, o presidente da associação francesa no momento do registo da organização, a 26 de Setembro de 1951, era Jeanne Levy-Jacquenin, sem profissão. Mas, cerca de um mês depois, o presidente passou a ser André Romieu, chefe do departamento para o consumo e distribuição da Secretaria de Estado dos Assuntos Económicos (fonte: Déclaration de Modification du 30 octobre 1951 - Préfecture de Police de Paris).
} 
a Altroconsumo, em Itália; a DECO, em Portugal; o CLCV, em França; ${ }^{11}$ $\mathrm{e}$, mais recentemente, o FDIC, no Brasil. Graças às estratégias de marketing directo da Conseur, a independência financeira das associações é garantida, pois recebem uma parte da receita da venda das revistas. Por outro lado, a influência nos conteúdos das respectivas revistas e as orientações da acção das próprias associações ficam limitadas pela posição maioritária da holding. Deste modo, por exemplo, o boicote não é promovido pela Conseur, pelo que ficará excluído do reportório de acção das associações que estão ligadas à holding; e a energia nuclear, sendo um tema sobre o qual a Conseur não se pronunciará pois cria divisões (Ryckeghem, 2005), também não será provavelmente discutido pelas associações.

No livro de Willy Van Ryckeghem (2005), L'Histoire de Test-Achats, este dirigente da associação belga conta como de uma associação se chegou a uma multinacional. $\mathrm{O}$ autor também explica porque o caso português é excepcional. A regra de ouro, como afirma, determina que quanto mais pequeno for o país, maior a penetração das organizações de consumidores, daí que a DECO seja um caso de sucesso, que de resto ultrapassa as expectativas. Com efeito, a DECO tem hoje mais de 300000 membros, ${ }^{12}$ o que representa cerca de $3 \%$ da população portuguesa.

Em suma, o modelo de consumidorismo anglo-saxónico dominante, personificado nas associações de consumidores que publicam revistas com testes comparativos, parece estabelecer ligações ambíguas com o sector lucrativo em resultado da procura da sua sustentabilidade económica e de uma acção mais eficaz e eficiente. E é neste contexto que destacamos o caso da DECO no quadro de uma rede europeia que orbita em torno da holding Conseur.

\section{A emergência do movimento de consumidores português e a recupe- ração do seu atraso}

De acordo com vários estudos, alguns de natureza internacional, que comparam Portugal com outras sociedades ocidentais, a participação cívica no país é baixa (Cabral et al., 2000; Eurostat, 2000; Viegas, 2004;

\footnotetext{
${ }^{11}$ A associação francesa consumerista UFC-Que Choisir estabeleceu, em 1969, um acordo com a Test-Achats semelhante ao celebrado entre a DECO e a Conseur. Este acordo terá contribuído para que a UFC-Que Choisir atingisse cerca de 280000 assinantes da revista. Em 1973, alguns líderes da UFC-Que Choisir romperam o acordo por recearem a perda de independência do movimento francês. Após este acordo, a associação francesa não voltou a aumentar significativamente o número de assinantes da revista, o que parece comprovar a eficácia da acção de marketing usada pela organização belga no aumento de receitas. Quando a Test-Achats cria a Conseur, no início da década de 1990, volta a abordar o consumidorismo francês mas desta vez o protocolo é celebrado com a Confederação de Alojamento e Condições de Vida (CLCV).

${ }^{12}$ Este número corresponde, em rigor, sobretudo a assinantes da revista, não havendo já adesões apenas como associado.
} 
Franco et al., 2005). Geralmente, esta avaliação é baseada em indicadores quantitativos como o número de associações, a taxa de filiação em associações ou de participação em acções de protesto.

As causas identificadas para este comportamento são múltiplas (Santos, 1994): desde o mau desempenho de factores geralmente considerados favoráveis à cooperação entre indivíduos, como o grau de escolaridade, à existência de mecanismos institucionais que têm impedido a livre associação, quer no século XIX quer no século XX.

No que diz respeito ao consumidorismo em particular, em que os valores de envolvimento associativo no nosso país seriam de aproximadamente $2 \%$ da população em 2001 (Viegas, 2004), a sua emergência moderna está dependente da existência, antes de mais, de uma sociedade de consumo. Ora, o desenvolvimento do mercado português é relativamente recente e rápido, sendo acelerado com o processo de integração do país na Comunidade Económica Europeia em 1986 (Schmidt, 1994).

A protecção do consumidor foi integrada no quadro jurídico, estando consagrada desde 1981, na lei de defesa do consumidor (alterada entretanto em 1996) e na própria Constituição da República Portuguesa, desde a revisão de 1982. E o consumidorismo, de um modo geral, tem vindo a introduzir-se na agenda dos mass media, o que é fundamental para que haja uma tomada de consciência e exercício dos direitos do consumidor.

Ainda que o consumidorismo português não se limite às organizações reconhecidas pelo Estado, ${ }^{13}$ na sequência da Lei-quadro 18 organizações de diferentes tipos (associações, organizações supra-associativas, sindicatos e cooperativas) têm hoje esse estatuto especial. A lei de defesa do consumidor confere-lhes vários direitos: o direito de representação dos consumidores em processos de consulta, o direito de solicitar a apreensão e retirada de bens do mercado e a interdição de serviços lesivos dos interesses dos consumidores, o direito de receber dinheiro do Estado para formação e para representar os consumidores, entre outros.

Neste sentido, a DECO é considerada uma organização de âmbito nacional e interesse genérico na medida em que tem pelo menos 3000 membros e a sua acção abrange todo o país e cobre todas as áreas de consumo. Nesta categoria encontramos quatro outras organizações ${ }^{14}$ mas nenhuma com um

\footnotetext{
${ }^{13}$ O movimento de consumidores compreende também associações de utentes e de contribuintes, entre outras (Freire e Silva, 1996), mas que não parecem respeitar os requisitos mínimos de dimensão para terem o reconhecimento e apoio do Estado.

${ }_{14}$ Referimo-nos à União Geral de Consumidores (UGC), à Federação Nacional de Cooperativas de Consumidores (FENACOOP), à Cooperativa de Consumo (PLURICOOP) e à Associação de Consumidores de Portugal (ACOP).
} 
tão elevado número de membros, nem possivelmente com idêntico dinamismo e visibilidade pública.

Em suma, podemos dizer que em Portugal foi criada uma rede de organizações públicas e privadas especificamente voltadas para a promoção dos direitos do consumidor a partir sobretudo dos anos 1980, embora as estruturas oficiais de defesa, controlo e informação dos consumidores ainda tenham carências em termos de recursos humanos, técnicos e económicos. Em todo o caso, no nosso país falar em defesa do consumidor é antes de mais falar da DECO.

\section{A profissionalização da DECO}

A profissionalização da DECO começou com a publicação da revista Proteste, em 1979, e a contratação dos primeiros trabalhadores a tempo inteiro. ${ }^{15} \mathrm{~A}$ procura de uma maior eficácia e de um desempenho com mais qualidade levou a associação à profissionalização (Meister, 1974), isto é, à sua crescente especialização na revista, à burocratização da organização e à sua institucionalização na sociedade portuguesa (Rego, 2007).

As dificuldades financeiras são no entanto importantes e dão origem a vários alertas aos membros. A longa história de cooperação entre a DECO e a associação belga Test-Achats cria a oportunidade para a venda dos direitos de publicação da revista à holding Conseur em 1989, o que vem a ser aceite pela Assembleia Geral da DECO.

É então criada a (actual) DECOPROTESTE, uma editora da qual a DECO detém $25 \%$ do capital, enquanto a Conseur detém os restantes $75 \%$. A decisão, que leva a associação a tornar-se um accionista minoritário da sua revista, dá origem ao que podemos chamar de turning point (Rego, 2007), tal foi o impacto nomeadamente na vida interna da associação.

Para além da perda de recursos humanos que antes se dedicavam à revista, obrigando a associação a diversificar as suas actividades, ${ }^{16}$ a DECO conquista independência financeira ao receber parte das receitas dos assinantes da revista. ${ }^{17}$ Com efeito, recorrendo a técnicas de marketing consideradas agressivas, como os mailings persistentes com ofertas de brindes, o número de assinantes da revista, e portanto de membros da DECO, aumenta de

\footnotetext{
${ }^{15}$ O conceito de profissionalização aqui empregue reporta-se à organização e não, como é habitual na literatura da sociologia das profissões, ao processo individual de aquisição do controlo sobre o exercício de uma determinada ocupação (Rego, 2007).

${ }^{16}$ Importa ter presente, em todo o caso, que desde a sua fundação, a DECO desenvolve várias actividades, entre as quais o apoio jurídico. Ao vender os direitos de publicação da Proteste, a associação diversificou as suas actividades desenvolvendo por exemplo formação.

${ }^{17}$ A qualidade de membro e assinante passam de resto a ser confundidas.
} 
forma muito expressiva. O número de membros, que ascendia a $30000 \mathrm{em}$ 1990, chega aos 275000 em 2004 (Pereira, 1999).

Podemos por conseguinte dizer que a associação, que começou por contar com o trabalho dos seus dirigentes na realização de testes em suas casas, no atendimento ao público em horário pós-laboral ou na redacção de pareceres jurídicos, passou de uma associação de tipo militante a uma associação sem membros (Skocpol, 1999). O trabalho voluntário foi dispensado e a participação dos membros desprezada.

Com efeito, foram sendo feitas alterações aos estatutos da DECO que vieram contribuir para a passividade dos membros na vida da associação e para a preservação do controlo do poder pelos dirigentes. Neste sentido, destacamos a revisão estatutária da associação de 1982 que estabelece o direito à cooptação. Esta medida garante aos membros da Direcção a possibilidade de escolherem um novo membro para substituir um dirigente quando este decide deixar o órgão executivo antes do final do mandato. Se a medida visa manter a estabilidade organizacional, não pode deixar de ser entendida também como uma forma de controlar o acesso ao poder. Salientamos ainda uma outra medida, adoptada com a revisão dos estatutos em 2002. A Direcção passa a ser obrigada a apresentar uma lista para a eleição seguinte. Se esta medida evita o vazio da Direcção, não pode deixar de contribuir, ao mesmo tempo, para desmobilizar candidaturas alternativas. Isto até porque há regras implícitas, que indicam que sempre existiu uma lista única, pelo que a mudança desse status quo seria arrojada e que a existência de várias listas seria sobretudo sinal de divisão interna quando a associação deve estar unida.

Se atentarmos na participação dos membros nas eleições dos órgãos sociais da associação, verificamos que ela é extremamente pequena e que não há mudanças significativas depois do turning point. Com efeito, em 1975, sete pessoas votaram no mandato de 1976-1977; em 1990, dezoito pessoas elegeram os órgãos sociais para 1991-1993; e em 2004, cento e trinta participaram nas eleições da associação (Rego, 2007). Note-se ainda que o ligeiro aumento na participação é devido à criação das delegações regionais em 1990, objectivo estatutário antigo. No entanto, nunca foi instituído o voto por correspondência.

Apesar da identificação das duas entidades, a DECO e a Conseur, na ficha técnica da revista, os meios de comunicação continuam a passar a ideia de que a revista é da associação DECO. A confusão entre as duas entidades, promovida desde logo pela semelhança dos seus nomes, é instrumentalizada. Com efeito, a venda da revista beneficiará da credibilidade inerente ao carácter não lucrativo que lhe está associado. 
A empresarialização ${ }^{18}$ da revista Proteste veio acelerar o processo de profissionalização da DECO nomeadamente fazendo emergir dirigentes com um duplo estatuto, isto é, indivíduos que assumem funções sociais e possuem também um vínculo laboral à associação ou ao seu universo. ${ }^{19}$ Com efeito, no pós-turning point foram convidados a integrar a Direcção o secretário-geral da DECO, responsáveis de uma empresa que a DECO criou no âmbito de um projecto a que concorrera ${ }^{20}$ e o director da editora. Se, por um lado, se garante assim que a imagem da DECO surge publicamente articulada, por outro lado configuram-se condições favoráveis à permanência destes dirigentes no poder.

Em suma, a legitimidade da intervenção da DECO na esfera pública reside hoje, claramente, na sua utilidade social (Juan, 1999), isto é, no seu papel de prestadora de serviços especializados, a membros e não membros, na sua contribuição para a regulação social, mais do que na representatividade dos seus membros. A representatividade continua, no entanto, a estar presente no discurso de muitos dirigentes e a ser usada como critério para a preponderância da DECO em conselhos consultivos da administração pública.

\section{Da aristocracia militante ao envolvimento profissional}

Quem são então os membros mais influentes e responsáveis por esta transformação da identidade da associação?

Num primeiro momento, uma caracterização do perfil sociodemográfico e ideológico dos dirigentes da DECO, desde a sua fundação em 1974 até 2005, mostra alguma homogeneidade do conjunto dos 42 entrevistados. As diferenças tornam-se mais nítidas quando comparamos o período pré com o pós-turning point.

As mulheres sempre foram minoritárias, mas têm um peso ainda menor no período pós-turning point, no início da década de 1990. De resto, a partir de 1996 a Direcção restrita, isto é, o Conselho Executivo, entretanto criado, deixa de integrar mulheres. Para compreender estes dados, não podemos esquecer que as primeiras a integrar a Direcção da DECO tiveram uma socialização familiar fortemente enquadrada pelo Estado Novo, que não preconizava a igualdade entre homens e mulheres. Muitas beneficiaram

\footnotetext{
${ }^{18} \mathrm{O}$ termo empresarialização reporta-se ao processo de mudança de personalidade jurídica da entidade responsável pela revista, que passou de uma associação sem fins lucrativos, a DECO, a uma sociedade comercial, a DECOPROTESTE.

${ }^{19} \mathrm{O}$ termo universo pretende referir a DECO e as empresas em que tem uma participação no capital: a editora DECOPROTESTE e a empresa DECOECO.

${ }^{20}$ Referimo-nos à empresa DECOECO, detida maioritariamente pela associação e depois também pelo seu director e dirigente da DECO.
} 
da relação com membros da Associação para o Desenvolvimento Económico e Social (SEDES), a associação da qual provêm vários fundadores da $\mathrm{DECO},{ }^{21}$ permitindo-lhes participar numa associação não politizada e com interesses próximos dos das donas de casa, como nos referiu uma dirigente. Para estas mulheres, o envolvimento na DECO é quase a única actividade fora de casa e portanto uma forma de emancipação, o que já não se verifica com as três mulheres que se tornaram dirigentes mais recentemente.

Quando a associação surgiu, em 1974, os dirigentes tinham idades compreendidas entre os 24 e 34 anos. Dado que os dirigentes se mantêm em funções, a idade mínima aumenta de mandato para mandato até meados de 1980. O envelhecimento dos dirigentes fundadores tende a ser compensado pela entrada de jovens profissionais da própria associação, nomeadamente nos mandatos de 1996 e 2000.

A escolaridade dos dirigentes é, em geral, elevada, o que confirma os resultados de outros estudos sobre os indivíduos mais participativos (Cabral, 2000; Wieviorka, 1977). Com efeito, dos 42 dirigentes entrevistados, apenas 5 não têm formação superior. Dos 37 com um curso universitário, 8 têm mais do que uma licenciatura. Ainda que haja desfasamentos geracionais, ${ }^{22}$ a universidade revela-se um espaço importante de socialização, onde se criam redes sociais que levam à DECO.

É de notar por fim que a actividade profissional geralmente é consistente com a formação escolar dos dirigentes. Os dirigentes da DECO são sobretudo especialistas das profissões intelectuais e científicas. Depois, há os quadros superiores da administração pública, dirigentes e quadros superiores de empresas e ainda um dirigente no grupo do pessoal administrativo e similares e outro no pessoal dos serviços e vendedores. ${ }^{23}$

Em suma, poderíamos dizer que, como afirma Jean-Yves Trépos (1982) a propósito da associação francesa UFC-Que Choisir, estamos perante uma aristocracia militante. Além disso, observamos que um perfil dirigente masculino e profissional (da associação) parece estar correlacionado com a profissionalização da associação, enquanto um envolvimento feminino e voluntário surge sobretudo nas fases iniciais.

\footnotetext{
${ }^{21}$ A SEDES foi criada em 1970 no quadro da abertura do regime ditatorial e foi conotada com a ala liberal do regime. Esta associação continua hoje a integrar nos seus órgãos sociais personalidades públicas, nomeadamente social-democratas e socialistas, assim como fundadores da DECO.

${ }^{22}$ Com efeito, identificam-se dirigentes dos primeiros mandatos que foram colegas de universidade, enquanto mais recentemente há dirigentes que chegam à DECO através de estágios profissionais, por exemplo.

${ }^{23}$ Usamos aqui as categorias da Classificação Nacional de Profissões.
} 


\section{Da neutralidade ideológica da associação}

Consideremos agora o perfil ideológico, isto é, a perfilhação religiosa, a filiação político-partidária e outras vinculações associativas dos dirigentes.

A socialização religiosa dos dirigentes da DECO passa geralmente por um envolvimento associativo. De facto, dos 42 entrevistados 15 estão ou estiveram ligados a pelo menos uma organização católica. De entre estes dirigentes, a grande maioria tem sido membro, e alguns mesmo líderes, da Juventude Escolar Católica (JEC) e da Juventude Universitária Católica (JUC). Importa ter presente que a DECO surge em 1974 e que até então a Igreja Católica tivera um papel importante e excepcional na dinamização da participação.

A simultaneidade de um envolvimento católico e consumidorista constata-se também no caso francês e belga ao nível dos seus fundadores. O primeiro presidente da UFC-Que Choisir, André Romieu, era próximo do catolicismo social (Pinto, 1992) e um dos fundadores mais influentes da Test-Achats, Gilbert Castelain, foi Secretário do Partido Social Cristão belga (PSC) até 1968 (Ryckeghem, 2005). Consideramos assim a hipótese de haver um envolvimento consumidorista correlacionado com um envolvimento católico.

Apesar das primeiras associações de consumidores no mundo se terem solidarizado com o movimento operário, desde a segunda metade do século XX o modelo dominante das associações de consumidores parece assumir uma via de acção colectiva neutra face à luta de classes. Conforme observa Michel Wieviorka (1977) para o caso francês, apenas os princípios do Partido Comunista não aceitam o modelo de consumidorismo que o modelo anglo-saxónico dominante preconiza. ${ }^{24}$ Mas esta neutralidade é aparente. Não podemos deixar de ter presente que pressupõe uma economia de mercado e não se opõe a ele. Neste sentido, o consumidor não pode deixar de cair dentro de uma área de produção ideológica, como também é possível a partir dele fazer distinções e exclusões (Pinto, 1990; 1992).

Não sendo nossa intenção analisar a influência dos partidos nas associações, consideramos ainda assim as filiações partidárias no âmbito da trajectória individual, antes de mais, com vista à identificação de redes de recrutamento. Assim, verificamos que metade dos dirigentes da DECO é militante ou simpatizante do Partido Socialista (PS); três são próximos, embora nenhum seja de momento militante, do Partido Social Democrata (PSD); dois são membros do Bloco de Esquerda (BE); e 16 não declaram espontaneamente ser militantes ou simpatizantes de qualquer partido político, sustentando que preferem manter-se neutros.

${ }^{24}$ Com efeito, no caso da DECO, os 42 entrevistados pertencem a todos os quadrantes políticos à excepção do comunista. 
Importa notar que se encontram dirigentes politicamente activos sobretudo até ao início dos anos 1990, havendo mandatos nos anos 1980 ocupados por uma esmagadora maioria de indivíduos membros ou simpatizantes do PS. O PS revelou-se ser uma fonte de recrutamento importante. Além disso, note-se que os dirigentes da DECO filiados no PS não são simples militantes de base do partido, pois assumiram, por exemplo, funções no Secretariado Nacional do partido (especialmente os dirigentes que desempenham funções sociais na $\mathrm{DECO}$ no período que precede e segue o turning point). Os membros próximos do PSD e do BE têm uma trajectória semelhante à dos dirigentes filiados ou simpatizantes do PS, na medida em que, no período pós-25 de Abril de 1974, integram o movimento católico ou aderem a pequenos partidos cujos membros acabam por se filiar depois sobretudo no PS.

Do total de entrevistados, quinze assumiram funções de confiança política ao longo das suas trajectórias individuais, tanto a nível governamental como municipal. Destes, treze já haviam exercido ou exerciam cargos políticos durante o período em que estiveram na direcção da DECO. Um dos casos mais importantes, quer pelo nível hierárquico do cargo público, quer por ocorrer nos primeiros anos da associação verifica-se em 1974 e 1975, quando um fundador da DECO foi simultaneamente ministro da II e III Governos Provisórios. A proximidade com o poder político está presente em toda a história da associação, embora tenda a ser um aspecto menos visível com a sua institucionalização.

Finalmente, no que diz respeito ao envolvimento em outras associações, de natureza não política, identificamos uma tendência clara para a multi-pertença, independentemente da fase de evolução da associação. Em média, estes dirigentes envolvem-se em 3,1 outras associações ao longo da sua trajectória. Os tipos de associações a que a maioria dos dirigentes da DECO pertence ou pertenceu são de natureza profissional, mesmo se desprezarmos o registo obrigatório em associações públicas profissionais. Depois surgem associações de estudantes, associações culturais ou científicas e também desportivas. Em qualquer caso, a DECO foi o seu envolvimento associativo mais importante, quer tendo em conta as funções assumidas, quer o tempo que permaneceram envolvidos.

O caso da DECO parece pôr assim em evidência um perfil de dirigente comum a organizações homólogas, a saber, a de um indivíduo socialmente activo, próximo do catolicismo e do centro político. Mas revela-nos também que este perfil tende a ser menos importante com a profissionalização da associação e em particular com a entrada de dirigentes recrutados a partir do universo DECO, altura em que a associação passará também a estar menos sujeita ao arbitrário. 


\section{O conceito de síndrome do fundador revisto}

O turning point na DECO implicou o abandono da associação por parte de alguns dirigentes que não concordavam com a estratégia de marketing que se começava então a praticar. Metade dos fundadores manifestou algum desconforto com a orientação seguida pela associação, sobretudo no que respeita às formas de angariação de novos membros. As saídas da associação destes dirigentes não são, contudo, motivadas por essa questão, uma vez que deixam os órgãos sociais antes do turning point. Os dirigentes fundadores que questionam as novas abordagens comerciais reconhecem em todo o caso que as técnicas publicitárias adoptadas são eficazes, proporcionando a independência financeira e uma maior visibilidade à associação.

Os dirigentes mais críticos são, contudo, os que assumiram funções depois do turning point e abandonaram entretanto a associação, ou seja, indivíduos que se envolveram com a associação num período em que ela já se confundia com a editora DECOPROTESTE. Embora esta não seja única razão para o seu afastamento, a falta de acordo sobre o que deve ser a associação terá contribuído para a sua saída. O número de dissidentes não afecta, contudo, a sobrevivência da associação e terá proporcionado até a mudança de perfil dos dirigentes, como vimos com o recrutamento de indivíduos com um vínculo laboral ao universo DECO.

A existência de um pequeno grupo de dirigentes fundadores, três homens e duas mulheres cujo conhecimento mútuo remonta à SEDES e que permanecera nos órgãos da associação praticamente ao longo de toda a sua história, parece ter garantido a continuidade da DECO. Apesar de dois deles não terem concordado com a venda dos direitos de publicação da revista à Conseur, um dos quais o próprio presidente da Direcção de então, assimilaram a mudança e contribuíram desse modo para a adesão de outros. Este grupo traz consigo a identidade associativa original, que de outra forma poderia ser esquecida. Note-se que três destes dirigentes ainda assumiam funções nos órgãos sociais no último mandato observado (2003-2005).

No caso da DECO, portanto, a sindrome do fundador não foi um obstáculo à profissionalização. Pelo contrário, este grupo de fundadores contribuiu para a aceitação da mudança, ao mesmo tempo que concorreu para a manutenção da imagem original da associação, a de uma organização pluralista e economicamente desinteressada.

De novo se constata aqui a semelhança com o caso francês e o caso belga, o que reforça a nossa percepção de um modelo comum de envolvimento dirigente consumidorista. Os dirigentes fundadores atrás identificados, ao permanecerem em funções sociais por vários mandatos, terão assegurado a continuidade ao longo do processo de crescimento e profissionalização. 


\section{Conclusão}

Apesar de recentemente o debate em torno das associações chamar a atenção para o carácter bíbrido das mesmas e questionar assim as abordagens arreigadas de ideologia associativa, poucos estudos dão conta da transformação no seio das próprias associações. Neste sentido, o caso da DECO evidencia um contributo importante para conhecermos a mudança do perfil dos dirigentes ao longo do crescimento da organização.

Ao procurar uma acção mais eficaz, a DECO profissionalizou-se e este processo conduziu à passagem de uma associação de tipo militante a uma associação sem membros. O recrutamento e a acção dos dirigentes evidenciam esta mudança.

Vimos, com efeito, que os dirigentes começam por ser recrutados de entre a rede de laços fortes (nomeadamente da SEDES, do meio universitário, do partido) e vão dando lugar ao recrutamento de gestores do universo DECO. O duplo estatuto destes novos dirigentes traduz-se na coexistência de interesses colectivos e individuais, o que contribui para a sua permanência no poder.

Em resultado do protocolo com a Conseur, a DECO tornou-se economicamente independente, ao mesmo tempo que perdia representatividade efectiva e via a sua acção constrangida pelo código de conduta da bolding.

A permanência de um núcleo de fundadores ao longo de todo o período de profissionalização foi particularmente importante para a manutenção da imagem associativa. A síndrome do fundador não é um problema que ponha em causa a mudança na DECO, antes permitiu a sua instrumentalização no quadro da relação estabelecida com o sector lucrativo.

A DECO inscreve-se no modelo anglo-saxónico consumidorista dominante, que se reproduz através de redes internacionais baseadas no princípio da economia de escala. Graças à DECO, o consumidorismo português ultrapassou o atraso, tendo hoje uma utilidade social (Juan, 1999) generalizada, quer enquanto organização empregadora, quer sobretudo enquanto instituição de protecção dos interesses dos consumidores. Mas esta organização há muito que se afastou do modelo de associação promovido pela ideologia associativa.

Sem pretendermos pôr em causa a importância destas associações na nossa sociedade, importará contudo reflectir sobre o seu suposto funcionamento democrático e sobre os critérios puramente demográficos consagrados pelo Estado para atestar a sua representatividade. 


\section{Referências bibliográficas}

Barthélémy, Martine (1994), "Le militantisme associatif", in Pascal Perrineau (org.), L'engagement politique - déclin ou mutation? Paris: Presses de la Fondation Nationale des Sciences Politiques, 87-114.

Cabral, Manuel Villaverde; Vala, Jorge; Freire, João (orgs.) (2000), Trabalho e cidadania - atitudes sociais dos portugueses, 1. Lisboa: Imprensa de Ciências Sociais.

Cerejo, António (2006), "Tribunal italiano exclui parceiros da DECO da lista de associações de consumidores”, Público, 20 de Julho.

Cohen, Joshua; Rogers, Joel (orgs.) (1995), Associations and democracy. London: Verso. Crozier, Michel; Friedberg, Erhard (1977), L'acteur et le système - les contraintes de l'action collective. Paris: Éditions du Seuil.

Eurostat (2000), La situation sociale dans l'Union Européenne 2000. Luxembourg: Office des Publications des Communautés Européennes.

Ferreira, Sílvia (2005), "O que tem de especial o empreendedor social? O perfil de emprego do empresário social em Portugal”, Oficina do CES, 223 (Março), 1-43.

Fillieule, Olivier; Mayer, Nonna (2001), "Devenirs militants - introduction", Revue française de science politique - devenirs militants, 51(1-2) (février-avril),19-25.

Franco, Raquel Campos et al. (2005), O sector não lucrativo português numa perspectiva comparada. Universidade Católica Portuguesa/Johns Hopkins University.

Freire, João; Silva, Carlos Dias (1996), Consumidores em movimento. Lisboa: CIES-ISCTE.

Gottlieb, Hildy (2003), Founder's Syndrome? Who Me?, consultado em 22/01/2010, http://www.help4nonprofits.com/NP_Bd_FoundersSyndrome_Art.htm.

Huff, Paula Rogers (2003), "Founder's syndrome and 4-H leaders organizations", consultado em 22/01/2010, http://www.uwex.edu/ces/4h/department/viewdocument. cfm?item=ACF4F9F.pdf.

Juan, Salvador (1999), "L'utilité sociale de l'activité associative face à la professionnalisation et à la 'marchandisation'”, Sociologie du Travail, 41(2), 195-207.

Laville, Jean-Louis; Sainsaulieu, Renaud (1997), Sociologie de l'association - des organisations a l'épreuve du changement social. Paris: Desclée de Brouwer.

Lewis, Henry D. (2002), "Founder's Syndrome: An Affliction for which There is Rarely Immunity”, Nonprofit Boards and Governance Review, consultado em 22/01/2010, www.fianationalnetwork.org/viewfile.cfv?id=1474.

Marchal, Emmanuelle (1987), "Le développement de l'emploi dans les associations et le phénomène de professionnalisation des activités associatives", Problèmes Économiques, 2047, 21-26.

Meister, Albert (1974), La participation dans les associations. Paris: Les Éditions Ouvrières. Micheletti, Michele et al. (orgs.) (2006), Politics, Products and Markets - Exploring Political Consumerism Past and Present. New Brunswick-London: Transaction Publishers. 
Middleton, Melissa (1987), "Nonprofit Board of Directors: Beyond the Governance Function", in Walter W. Powell (org.), The nonprofit sector - a research bandbook. New Haven-London: Yale University Press, 141-153.

Miller-Millesen, Judith L. (2003), "Understanding the Behaviour of Non-Profit Boards of Directors: A Theory-Based Approach”, Nonprofit and Voluntary Sector Quaterly, 32(4), 521-547.

Newton, Kenneth (2002), "Social Capital and Democracy in Modern Europe", in Jan W. Van Deth et al. (orgs.), Social Capital and European Democracy. London-New York: Routledge, 3-24.

Pereira, Raul da Silva (1999), DECO - 25 anos em defesa dos consumidores. Lisboa: Edição DECO.

Pinto, Louis (1990), "Le consommateur: agent économique et acteur politique”, Revue Française de Sociologie, XXXI, 179-198.

Pinto, Louis (1992), "La gestion d'un label politique: la consommation", Actes de la Recherche en Sciences Sociales, 91-92, 3-19.

Putnam, Robert D. (1994), Making Democracy Work-Civic Traditions in Modern Italy. Princeton: Princeton University Press.

Rego, Raquel (2007), Dirigentes associativos: envolvimento e profissionalização/ Dirigeants associatifs: engagement et professionnalisation, tese de doutoramento em sociologia, ISCTE-Université Lille 1.

Ronit, Karsten (2007), "Modes of Consumer Participation and Engagement in the Making of Global Consumer Policy”, in Karsten Ronit (org.), Global Public Policy - Business and the Countervailing Powers of Civil Society. Oxon-New York: Routledge, 65-88.

Rosenblum, Nancy L. (2000), Membership and Morals - The Personal Uses of Pluralism in America. Princeton: Princeton University Press.

Ryckeghem, Willy Van (2005), L'bistoire de Test-achats - d'une revue de consommateurs à une multinationale. Bruxelles: Éditions Racine.

Salamon, Lester M. et al. (1999), "Civil Society in Comparative Perspective”, in Lester M. Salamon et al., Global Civil Society - Dimensions of the Nonprofit Sector. Baltimore: Johns Hopkins Center for Civil Society Studies, 3-39.

Santos, Boaventura de Sousa (1994), Pela mão de Alice - o social e o político na pós modernidade. Porto: Edições Afrontamento.

Schmidt, Luísa (1994), Con-sumo bem espremido. Lisboa: Gradiva.

Skocpol, Theda (1999), "Associations without members", The American Prospect, 10 (45), consultado em 22.01.10, http://www.prospect.org/cs/articles? article=associat ions_without_members.

Tchernonog, V.; Hély, M. (2003), "Les formes de l'action associative - essais de typologie à partir d'une enquête statistique", in Prouteau, Lionel (org.), Les associations entre bénévolat et logique d'entreprise. Rennes: Presses Universitaires de Rennes, 25-47. 
Trépos, Jean-Yves (1982), Contribution a une sociologie du militantisme dans les organisations de consommateurs, thèse pour le doctorat de 3ème cycle en sociologie, Université des Sciences et Techniques de Lille.

Viegas, J. M. Leite (2004), "Implicações democráticas das associações voluntárias - o caso português numa perspectiva comparativa europeia”, Sociologia-problemas e práticas, 46, 33-50.

Vieira, Paula (2001), “Associativismo: problematizar o seu potencial para estruturar e enriquecer as relações sociais”, Cadernos de ciências sociais, nº 21-22, 151-218.

Warren, Mark E. (2001), Democracy and Association. Princeton: Princeton University Press.

Weiss, Dimitri; Chirouze, Yves (1984), Le consumérisme. Paris: Sirey.

Wieviorka, Michel (1977), L'Etat, le patronat et les consommateurs. Paris: Puf. 